\title{
Efficacy and safety of radiotherapy for primary liver cancer
}

\author{
Wenqi Chen ${ }^{1,2}$, Chi-Leung Chiang ${ }^{3,4,5}$, Laura A. Dawson ${ }^{6,7}$ \\ ${ }^{1}$ Department of Clinical Oncology, The University of Hong Kong-Shenzhen Hospital, Shenzhen, China; ${ }^{2}$ Medical College, University of South \\ China, Hengyang, China; ${ }^{3}$ Department of Clinical Oncology, The University of Hong Kong, Hong Kong, China; ${ }^{4}$ Department of Clinical Oncology, \\ Queen Mary Hospital, Hong Kong, China; ${ }^{5}$ Department of Clinical Oncology, Tuen Mun Hospital, Hong Kong, China; ${ }^{6}$ Radiation Medicine \\ Program, Princess Margaret Hospital, University Health Network, Toronto, Ontario, Canada; ${ }^{7}$ Department of Radiation Oncology, University of \\ Toronto, Toronto, Ontario, Canada \\ Contributions: (I) Conception and design: LA Dawson, W Chen; (II) Administrative support: W Chen; (III) Provision of study materials or patients: \\ W Chen, CL Chiang; (IV) Collection and assembly of data: W Chen, CL Chiang; (V) Data analysis and interpretation: W Chen, LA Dawson; (VI) \\ Manuscript writing: All authors; (VII) Final approval of manuscript: All authors. \\ Correspondence to: Laura A. Dawson, MD. Radiation Medicine Program, Princess Margaret Hospital, University Health Network, Toronto, Ontario, \\ Canada. Email: Laura.Dawson@rmp.uhn.ca.
}

\begin{abstract}
Primary liver cancer includes hepatocellular carcinoma (HCC, 75-85\%) and intrahepatic cholangiocarcinoma (10-15\%). The vast majority of patients with primary HCC are not candidates for surgical treatment. Surgical resection, liver transplantation and percutaneous puncture are effective potentially curable treatments for patients with early stage liver cancer. Radiation therapy is a non-surgical alternative treatment that has generally been used to treat patients with advanced liver cancer, although it's use in the potentially curative setting is increasing. Radiotherapy is a non-invasive local treatment which works through ionizing radiation. This review summarizes the efficacy and safety of commonly used radiotherapy methods, and reviews three-dimensional conformal radiotherapy (3DCRT), intensity modulated radiation therapy (IMRT), stereotactic body radiotherapy (SBRT), volume-modulated arc therapy (VMAT), and internal radiation therapies, for primary liver cancer (in particular for HCC).
\end{abstract}

Keywords: Primary liver cancer, hepatocellular carcinoma (HCC); radiotherapy; internal radiation therapy; tumor

Submitted Feb 19, 2020. Accepted for publication May 14, 2020.

doi: 10.21037/cco-20-89

View this article at: http://dx.doi.org/10.21037/cco-20-89

\section{Introduction}

\section{Primary liver cancer}

Primary liver cancer includes hepatocellular carcinoma (HCC) (75-85\% of cases) and intrahepatic cholangiocarcinoma (10-15\% of cases), and other less common tumors, such as fibrolamellar HCC (1). Primary liver cancer generally has a high potential for vascular and metastatic spread and a poor prognosis. The average life span after diagnosis is 6-20 months, with 3- and 5-year survival rates of $72 \%$ and $50 \%$ respectively after surgery, and the 5 -year survival rate from $48 \%$ to $61 \%$ after liver transplantation, both for patients with early stage HCC (2-4).

HCC is one of the most common causes of cancerrelated death globally. Its incidence is highest in areas with high incidence of hepatitis B (HBV) and hepatitis C (HCV), particularly in Southeast Asia and Sub-Saharan Africa (5-8). According to the 2019 GLOBOCAN estimated, there are approximately 42,030 new liver cancer cases diagnosed, and 31,780 liver cancer deaths (9). This review mainly focuses on the usage of radiotherapy in HCC.

\section{Treatment of primary liver cancer}

For HCC, surgical resection and/or liver transplantation remain the first-line treatment options for radical treatment with the goal of cure. Most patients with HCC do not present with symptoms until their tumor is at an advanced, often incurable, stage. The vast majority of patients are not candidates for surgical treatment. The current surgical 
resection rate is only $20 \%(10)$. According to Guide to the Treatment of Hepatocellular Carcinoma from the American Association for the Study of the Liver Diseases (AASLD), surgical resection, liver transplantation and percutaneous puncture are effective for very-early and early stage HCC patients (Child-Pugh A, tumor diameter $<3 \mathrm{~cm}$ ); for whom the median OS is longer than 60 months, and the 5 -year survival rate is $50-70 \%(3,11,12)$. Unfortunately, patients with macro and/or microvascular invasion, as well as patients with multifocal tumor, have a worse prognosis despite surgergical resection, with a 5 -year recurrence rate of $70 \%$ or higher $(13,14)$. Non-surgical treatments such as transcatheter arterial chemoembolization (TACE), chemotherapy, molecular targeted drugs, are generally reserved for treatment of these patients with intermediate and advanced liver cancer (15-17). There is emerging experience and ongoing clinical trials of the use of radiotherapy to treat such patients with intermediate and advanced HCC.

\section{Radiotherapy for primary liver cancer}

Radiotherapy is a non-invasive local treatment that works through ionizing radiation that causes direct and indirect DNA double strand breaks (18). Liver tumors are sensitive to radiation treatment, with moderate to high radio sensitivity, next to very radiosensitive tumors of the bone marrow and lymphatic tissue and normal tissues such as the bone marrow and kidney (19). Mechanically, the energy of ionizing radiation directly or indirectly acts on biological macromolecules such as nucleic acids, proteins, enzymes, etc., and through irradiation of water to produce ionization that reduce or disable their normal function, and lead to unrepairable double strand DNA breaks (20). The normal liver has a strong ability to regenerate, and the spared normal tissue can compensate for the radiation-induced focal damaged liver, by the hepatic cell proliferation of the spared liver.

Radiotherapy for HCC has undergone a series of technical advances over the decades from whole-liver wide field low dose irradiation, to local field irradiation, moving strip radiotherapy, and hyper-fractionation radiotherapy that now can be delivered quite conformally around focal liver tumors. Prior to the 1990s, large volume liver irradiation led to damage to normal liver, which frequently led to radiation-induced liver disease (RILD), liver failure or even death if excessive doses were delivered to the full liver (21). Therefore, there was a delay in the use of focal radiation therapy used with curative intent. With the application of three-dimensional conformal radiotherapy (3DCRT), intensity modulated radiation therapy (IMRT), and stereotactic body radiotherapy (SBRT), the accuracy of the lesion targeting was significantly improved while the radiation dose on the surrounding normal tissues was able to be substantially reduced. With recent advanced imaging and radiation treatment technologies, the risk of serious complications has been substantially reduced. At present, radiotherapy has become an indispensable part of comprehensive treatment for HCC (22-25). It is included as a prioritized treatment across early, intermediate and advanced HCC patients in some country guidelines [e.g., Korean (26)], but reserved as treatment options only if other standard treatments are not feasible in other treatment guidelines [e.g., NCCN (27)].

Radiotherapy can be classified into external radiation therapy and internal radiation therapy (using a variety of radiation sources) (18). External radiation therapy mainly includes SBRT, 3DCRT, IMRT and volume-modulated arc therapy (VMAT), using photon-based radiation therapy. Protons and carbon ions have also been used to treat patients with liver cancer, but they are more expensive and less widely available (28-30). Internal radiation therapy includes ${ }^{90} \mathrm{Y}$ microsphere therapy, ${ }^{131} \mathrm{I}$ monoclonal antibody, radioactive iodinated oil and ${ }^{125} \mathrm{I}$ particle implantation, often delivered via the hepatic artery. Percutaneous brachytherapy has also been used to treat liver cancer (31). This article analyzes the effectiveness and safety of various radiotherapy techniques in different stages of liver cancer (in particular for HCC). A summary of studies regarding the response rate and overall survival of radiotherapy for primary liver cancer is listed in Table 1.

\section{External radiotherapy}

\section{Three-dimensional conformal radiation therapy (3DCRT)}

In recent years, 3DCRT has been commonly used in liver cancer (32). This therapy is based on advances in computer computation, optimization and virtual reconstruction technology. Radiation target volumes and field shapes and angles are designed with the help of a radiotherapy treatment planning software system that calculated dose in a patient model based on a CT scan of the patient in treatment position. The target dose is calculated according to the tolerance doses of adjacent normal tissues and the underlying liver (33). 
CRT allows the sparing of normal tissues such as the liver, by reducing acute and late adverse reactions, and it thus substantially improves the therapeutic ratio when used to treat patients with liver cancer (34). A challenge of 3D-CRT is that liver movement occurs due to respiratory, which impacts the accuracy in locating and irradiating the liver tumor. If the irradiated liver volume is too high, the risk of liver toxicity may increase (35). More recently, strategies have become available to reduce the negative impact of respiratory motion of the liver such as liver immobilization through active breath hold, gating radiation therapy to one phase of the breathing cycle or tracking the radiation beam with the moving liver $(36,37)$.

3DCRT has been used to treat early stage liver cancer, with local control rates of $71.4 \%$ (38) to $93.8 \%$ (39) at more than one month, and one year overall survival of $73.6 \%$ (40) to $81.1 \%$ (39). Outcomes are best in patients with single and small HCCs (less than $10 \mathrm{~cm}$ ) compared to those with larger, multifocal cancers with vascular invasion (39). Mornex et al. had treated 25 patients with a single HCC (diameter $<5 \mathrm{~cm}$ ) or with two tumors (diameter $<3 \mathrm{~cm}$ ) using a total dose of 66 Gy (33 daily fractions over 6 weeks). This treatment achieved a local control rate of $92 \%$ at more than three months (24). Another 3DCRT study included 198 HCC patients with tumors smaller than $10 \mathrm{~cm}$ and not eligible for surgical resection or local ablation therapy. One the group was treated with a median total dose of $52 \mathrm{~Gy}$ (with a fraction of 5.0-7.0 Gy, three fractions a week), the other group received a median total dose of 53 Gy (with a fraction of 2.5-4.9 Gy, three fractions a week); the former had a better survival. Overall, for the entire study population, the one year overall survival was $73.6 \%$, which suggests that 3DCRT is and effective ablative therapy for small HCC (40). The local control rate of $71.4 \%$ in small HCC (size $<5 \mathrm{~cm}$ ) was conducted by Park et al. (38). Similar studies using 3DCRT for small HCC showed favorable results $(41,42)$.

For advanced liver cancer, 3DCRT has been associated with good short-term efficacy.

3DCRT is one of the most effective treatments for HCC with portal-vein/inferior-vena-cava tumor invasion, thrombosis or emboli. Tang et al. analyzed 371 patients with liver cancer with portal vein tumor emboli who received surgery (186 cases) and 3DCRT (185 cases). The 1 -, 2-, and 3-year survival rates of the radiotherapy group were $51.6 \%, 28.4 \%$, and $19.9 \%$, respectively; the survival rates of the surgery group were $40.1 \%, 17.0 \%$ and $13.6 \%$, respectively (43). Lim et al. treated 45 HCC patients with portal vein tumor emboli with 3DCRT from 38 to $65 \mathrm{~Gy}$ in fractions. The results demonstrated that $6.7 \%$ patients achieved CR, 55.6\% had PR, 31\% showed SD, and PD occurred in $6.7 \%$. No RILD was found during the longterm survivors (44). Similarly, Kouloulias et al. reported 9 patients with $60 \%$ response rate and a total survival of 24 months (45). Yoon et al. analyzed the efficacy of radiation therapy combined with TACE based on 412 patients with portal vein tumor emboli, and reported that 3DCRT had a local control rate of $27.9 \%$ (3.6\% CR and $24.3 \% \mathrm{PR}$ ); the 1-year and 2-year survival rates were $42.5 \%$ and $22.8 \%$; the local control from radiation therapy was an independent prognostic factor, and the median survival time of those who had stable or responding HCC was 19.4 months (46).

\section{IMRT}

IMRT is a newer technology developed on the basis of 3DCRT. Using optimization software, based on multi-field irradiation, the dose intensity of each field within larger fields can be varied, and the radiation dose in the target area may be more evenly distributed, and more tightly surrounding the target volume, sparing concave or convex adjacent normal tissues, which is beneficial for protecting important sensitive organs. It is more suitable for treating tumors with irregular three-dimensional shapes. The disadvantages of IMRT are the longer exposure time and poor tolerance in patients with severe illness $(47,48)$.

Most of the IMRT series have focused on advanced liver cancer patients, with a local control rate from $30 \%$ to $50 \%$ for advanced HCC $(49,50)$. For tumors with a margin less than $1 \mathrm{~cm}$ adjacent to or involved in the hilar vascular trunk, IMRT is helpful for those who will receive surgery. IMRT improved the 3-year OS and disease-free survival in HCC patients receiving narrow margin hepatectomy. A study analyzed 181 patients with central liver cancer showed that proximal resection marginal plus IMRT for patients had similar achieve OS and recurrence-free survival to those with wide resection margins (50). Retrospective analysis of 136 patients with microvascular invasion (MVI) demonstrated that radiotherapy following hepatectomy could improve survival outcomes in comparison with TACE or conservative treatment. This treatment strategy is highly effective for patients with a narrow surgical margin (51). A prospective randomized study was conducted by $\mathrm{Yu}$ et al. which recruited 119 HCC patient who had narrowmargin $(<1 \mathrm{~cm})$ hepatectomy and showed a higher trend 


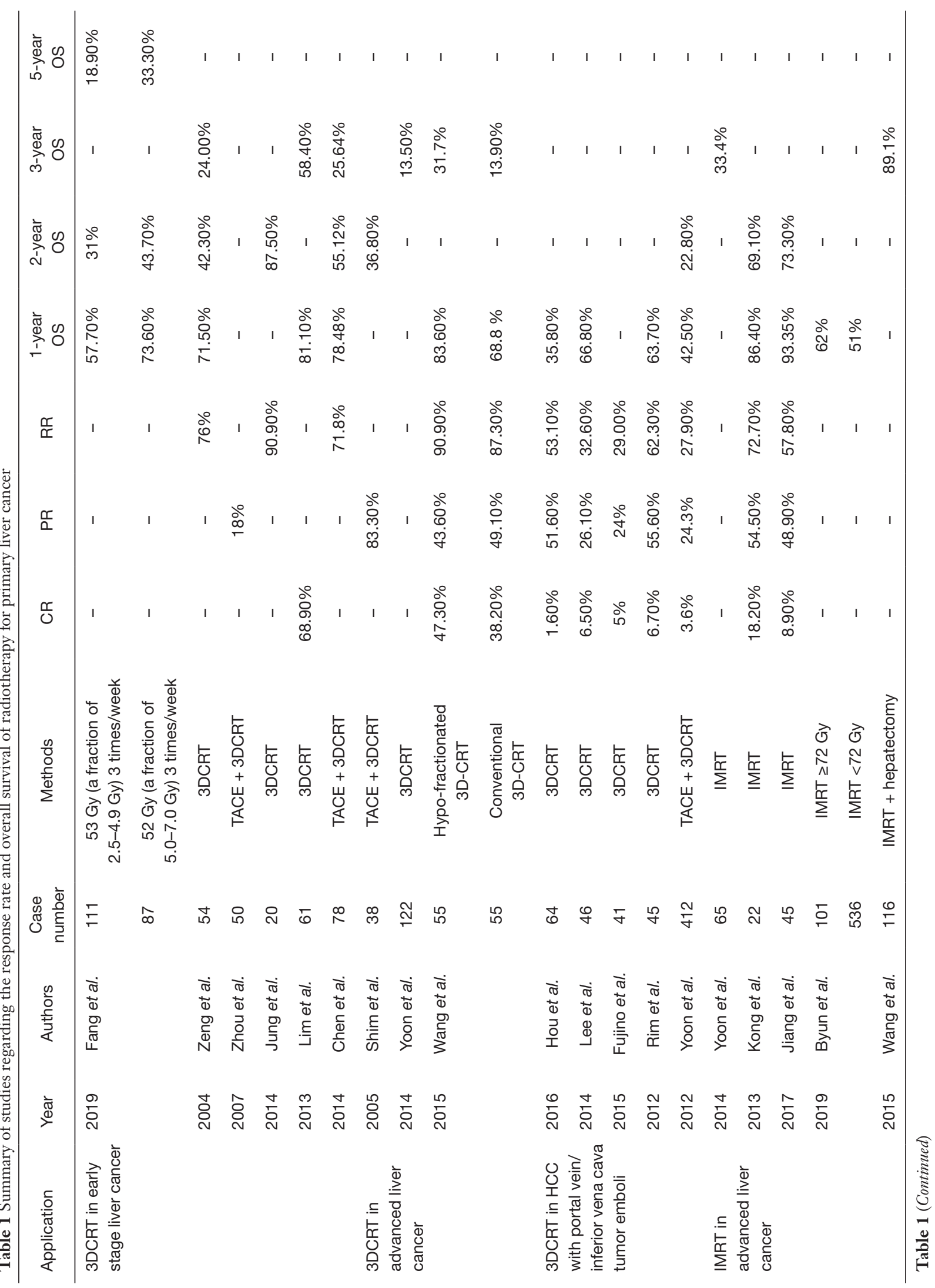




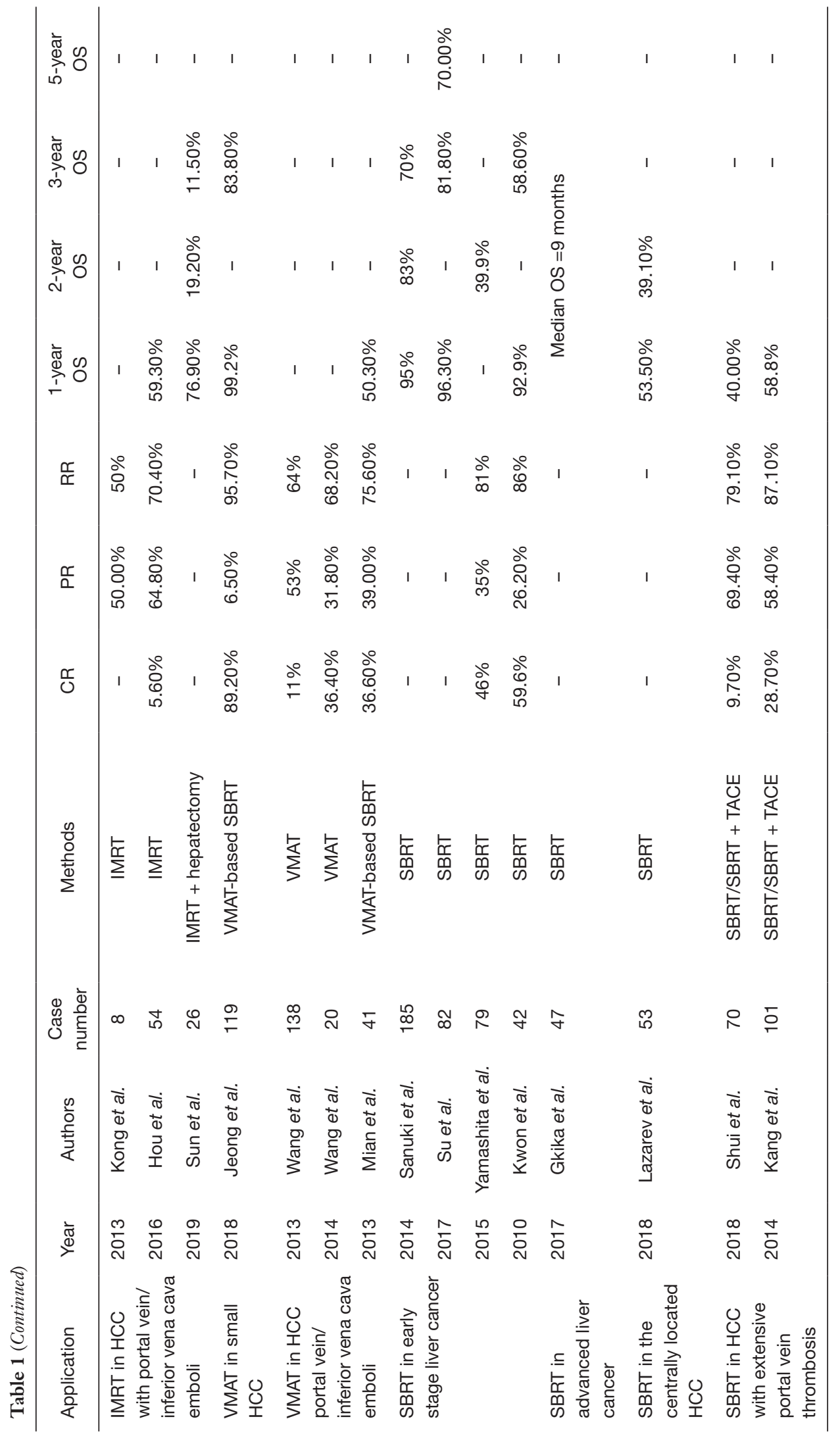


in adjuvant RT group of one-, 3-, and 5-year recurrencefree survival rates than that in control group (52). Besides, combined application of IMRT and TACE can significantly improve the prognosis of HCC patients. A study observed 26 liver cancer patients with portal tumor thrombus $(87 \%$ were in III-IV stage) and found the patients under the combined treatment of IMRT and TACE (the median dose of radiotherapy was $50 \mathrm{~Gy}, 44-70 \mathrm{~Gy}$ ) had an effective rate of $64.8 \%$ and a median survival of 20.2 months (53).

\section{Volumetric modulated arc therapy (VMAT)}

VMAT is a dynamic IMRT method with the advantages of delivering irradiation via a rotating gantry. It may be used in combination with active breathing coordinator (ABC) to immobilize the liver. When compared with 3DCRT or IMRT, it is superior in dose conformity. VMAT provides a more accurate target area, with lower organ-endangering dose and less radiation liver injury $(8,54,55)$. Wang et al. treated 138 HCC patients $(88.4 \%$ of patients in AJCC stage III or IV) with VMAT, with radiotherapy doses of 45,60 , and 66 Gy (once 1.8 or 2 Gy) and finally evaluated 108 patients. All participants were classified as BCLC stage A-C. They showed 11\% CR, 53\% PR, 29\% SD, and 6\% PD cases at a total follow-up of maximum 28 months. The median survival time was 10.6 months, the local control rate at 6 and 12 months were $95 \%$ and $93.7 \%$, respectively; no serious toxic events occurred (54).

\section{SBRT}

SBRT is a radiotherapy method that combines stereotactic technology and 3DCRT. With image guidance and respiratory motion management technology, SBRT can accurately target the tumor area and launch a high dose in the centre of the tumor, while the dose outside the target area decreases sharply. Thereby, normal tissue close around the tumor can be well protected from radiation. SBRT allows irradiation to be delivered in fewer fractions than conventional radiation therapy (1 to 6 over one to two weeks, versus 25 to 35 over 5 to 7 weeks) and requires high precision delivery with daily image guidance $(56,57)$.

SBRT is most successful in the treatment of smaller liver cancers, and early reports have focused on early stage HCC. Although the local control rate is reduced in larger tumors, the majority of tumors larger than $10 \mathrm{~cm}$, are controlled following modest dose SBRT 1 to 2 years post SBRT (58). Andolino et al. followed up 60 patients with HCC who had received SBRT. Their median tumor diameter was $3.2 \mathrm{~cm}$, the dose was $42 \mathrm{~Gy} / 3$ fractions, the local control rate was $90 \%$ for two years, the 2 -year PFS rate was $48 \%$, and the 2 -year OS rate was $67 \%$; as expected, no RILD events occurred (59). Kwon et al. treated 42 HCC patients with dosed from 30 to $39 \mathrm{~Gy} / 3$ fractions; they observed a CR of $60 \%$ and PR of $26 \%$, and the $1-$ and 3 -year PFS rates were $72 \%$ and $67.5 \%$, respectively (60). In another retrospective study, patients with Child-Pugh A $(n=137)$ received radiotherapy doses of $40 \mathrm{~Gy} / 5$ fractions and patients with Child-Pugh B $(n=48)$ liver dysfunction received $35 \mathrm{~Gy} / 5$ fractions. The 3 -year local control rates were $89 \%$ and $91 \%$, the OS rates were $72 \%$ and $66 \%(61)$. Takada et al. used SBRT to treat 50 small-HCC patients and confirmed that the dose of $30 \mathrm{~Gy} / 5$ fractionswas safe and effective for patients with cirrhosis (62).

There is an overlap in the indications of SBRT and radiofrequency ablation therapy for small HCC, and they were compared in some studies. Rajay Urgur et al. analyzed the prognosis of non-chemotherapy-and-non-metastatic HCC treated by radiofrequency ablation or SBRT in the National Cancer Database (NCDB) from 2004 to 2013. There were 3,684 patients receiving radiofrequency ablation and $2 \%$ receiving SBRT. The OS in the radiofrequency ablation group was significantly better than that in the SBRT group, and this advantage remained after pairing with propensity scores $(\mathrm{P}<0.05)(63)$. However, a study by Wahl et al. retrospectively analyzed the prognosis of 224 patients with non-surgical-and-non-metastatic HCC. Among them, 161 were treated with radiofrequency ablation, and 63 were treated with SBRT. The results showed that the radiofrequency ablation treatment group had $83.6 \%$ PFS rate within 1 year and $80.2 \%$ within 2 years, respectively; while the SBRT group showed $97.4 \%$ and $83.8 \%$ PFS rate respectively, there were no significant differences between two groups. Also, there were no differences in the OS rates. However, when the diameter was greater than $2 \mathrm{~cm}$, the SBRT group had a better outcome than radiofrequency ablation treatment (64).

For patients with advanced HCC, SBRT has also been useful. Chan et al. performed SBRT on 16 advanced HCC patients at a dose of $45 \mathrm{~Gy} / 10$ fractions. The local control rate was $91 \%$, and the 1 - and 3 -year survival rates were $62 \%$ and $28 \%$, respectively (65). Other studies showed that the local control rate of SBRT for patients with larger, more advanced HCC, often invading the portal vein, ranged from $63 \%$ to reached $87 \%$; the median survival time ranged from 12.9 to 17 months; the 1 -year and 3 -year survival rates were $87 \%$ and $55 \%$, respectively $(58,66)$, with a risk from liver toxicity ranging from $10 \%$ to $30 \%$. 


\section{Proton and heavy ion radiotherapy}

Proton and heavy ion radiotherapy have a potential benefit of less low dose splash to adjacent normal tissues, which may be helpful for deep liver tumors and/or for patients with impaired liver function (67). The proton and carbon ion radiotherapy doses are deposited within the body in a Bragg peak, with a sharp falloff of dose in the normal tissues beyond the target volume. Proton and heavy ion radiotherapy have some other potential advantages to photons, in addition to the sharp drop in dose after the Bragg peak; these include a higher line energy transfer, high relative biological effectiveness, and low oxygen effect. By adjusting the energy, the Bragg peak may be localized at the depth of the tumor, which kills the tumor cells and protects the normal tissues around the tumor (68). Nakayama applied proton radiotherapy to treat $47 \mathrm{HCC}$ patients at a dose of $72.6 \mathrm{~Gy} / 22$ fractions or $77 \mathrm{~Gy} / 35$ fractions. In this work, the median OS time was 33.9 months, the 3 -year local control rate reached $88.1 \%$, and the total 3 -year survival rate was $50 \%$. In the end, $6.4 \%$ and $2.1 \%$ of patients were reported grade 2 and 3 gastrointestinal reactions, respectively (69). Lee et al. studied 27 HCC patients with portal vein tumor thrombi using proton radiotherapy (50 to $66 \mathrm{~Gy} / 20$ to 22 fractions). They acquired an outcome of $55.6 \% \mathrm{PR}, 37 \% \mathrm{SD}$, and $7.4 \% \mathrm{PD}$ cases (70). Imada et al. carried out a prospective study enrolling 64 HCC patients with portal vein tumor thrombus. Among them, 18 liver tumors were close to the thrombus $(<2 \mathrm{~cm})$, and the remaining 46 tumors were far away from the thrombus. The radiation dose was set as $52.8 \mathrm{~Gy} / 4$ fractions. In the end, the 5-year survival rate of 18 patients (whose tumors were close to the thrombus) was $22.2 \%$, and the local control rate reached $87.8 \%$. For 46 patients whose tumors were far away from the thrombus, the 5 -year survival rate was $34.8 \%$ and local control rate was $95.7 \%$, respectively (71).

\section{Internal radiotherapy}

Internal radiation therapy takes advantages of the natural cavity or tissue space of the human body to directly place or implant a radioactive source. Using catheters, the radioactive source was sent into the target and highdose radiation can be applied in a low volume (72). At present, the internal radiation treatment of primary liver cancer mainly uses selective internal radioembolization therapy (SIRT), including ${ }^{90} \mathrm{Y}$ microsphere, ${ }^{131} \mathrm{I}$ monoclonal antibody, radioactive iodinated oil, and ${ }^{125} \mathrm{I}$ particle implantation. Among them, application of ${ }^{90} \mathrm{Y}$ microsphere radiotherapy can prolong the survival of HCC patients and can downgrade large tumors to meet the liver transplantation standards (73-75). There is evidence that SIRT can provide the survival benefit is comparable to TACE (76). When compared with SBRT, SIRT also showed similar results in overall and disease-specific survival benefit in unresectable HCC (77). More randomized trials need to conduct to compare SIRT with various modalities to therapy HCC in the future.

\section{Conclusions}

Radiotherapy is becoming an indispensable component of comprehensive treatment of primary HCC. The optimal role of radiotherapy, the exact radiotherapy strategy, as well as ideal sequencing are largely unknown; factors to consider in multi-disciplinary decision making include the tumor number, volume, location, and whether there is portal venous tumor invasion, in addition to liver function and patient performance status. Randomized trials of radiation therapy are ongoing and make help to elucidate the role of radiation therapy in this setting.

\section{Acknowledgments}

Funding: None.

\section{Footnote}

Provenance and Peer Review: This article was commissioned by the Guest Editors (Mehmet Akce and Shishir K. Maithel) for the series "Hepatocellular Carcinoma" published in Chinese Clinical Oncology. The article was sent for external peer review organized by the Guest Editors and the editorial office.

Conflicts of Interest: All authors have completed the ICMJE uniform disclosure form (available at http://dx. doi. org/10. 21037/cco-20-89). The series "Hepatocellular Carcinoma" was commissioned by the editorial office without any funding or sponsorship. LAD reports nonfinancial support from Merck, non-financial support from Bayer, during the conduct of the study. The authors have no other conflicts of interest to declare.

Ethical Statement: The authors are accountable for all aspects of the work in ensuring that questions related 
to the accuracy or integrity of any part of the work are appropriately investigated and resolved.

Open Access Statement: This is an Open Access article distributed in accordance with the Creative Commons Attribution-NonCommercial-NoDerivs 4.0 International License (CC BY-NC-ND 4.0), which permits the noncommercial replication and distribution of the article with the strict proviso that no changes or edits are made and the original work is properly cited (including links to both the formal publication through the relevant DOI and the license). See: https://creativecommons.org/licenses/by-nc-nd/4.0/.

\section{References}

1. Bray F, Ferlay J, Soerjomataram I, et al. Global cancer statistics 2018: GLOBOCAN estimates of incidence and mortality worldwide for 36 cancers in 185 countries. CA Cancer J Clin 2018;68:394-424.

2. Hartke J, Johnson M, Ghabril M. The diagnosis and treatment of hepatocellular carcinoma. Semin Diagn Pathol 2017;34:153-9.

3. Bruix J, Sherman M, American Association for the Study of Liver D. Management of hepatocellular carcinoma: an update. Hepatology 2011;53:1020-2.

4. Yoo HY, Patt CH, Geschwind JF, et al. The outcome of liver transplantation in patients with hepatocellular carcinoma in the United States between 1988 and 2001: 5 -year survival has improved significantly with time. J Clin Oncol 2003;21:4329-35.

5. Venook AP, Papandreou C, Furuse J, et al. The incidence and epidemiology of hepatocellular carcinoma: a global and regional perspective. Oncologist 2010;15 Suppl 4:5-13.

6. Torre LA, Bray F, Siegel RL, et al. Global cancer statistics, 2012. CA Cancer J Clin 2015;65:87-108.

7. Grandhi MS, Kim AK, Ronnekleiv-Kelly SM, et al. Hepatocellular carcinoma: From diagnosis to treatment. Surg Oncol 2016;25:74-85.

8. Gong GZ, Yin Y, Xing LG, et al. RapidArc combined with the active breathing coordinator provides an effective and accurate approach for the radiotherapy of hepatocellular carcinoma. Strahlenther Onkol 2012;188:262-8.

9. Siegel RL, Miller KD, Jemal A. Cancer statistics, 2019. CA Cancer J Clin 2019;69:7-34.

10. Meng-chao W. Progress in Diagnosis and Treatment of Primary Liver Cancer. Zhongguo Yi Xue Ke Xue Yuan Xue Bao 2008;30:363-5.

11. Llovet JM, Bru C, Bruix J. Prognosis of hepatocellular carcinoma: the BCLC staging classification. Semin Liver Dis 1999; 19:329-38.

12. Llovet JM, Fuster J, Bruix J, et al. The Barcelona approach: diagnosis, staging, and treatment of hepatocellular carcinoma. Liver Transpl 2004;10:S115-20.

13. Shah SA, Greig PD, Gallinger S, et al. Factors associated with early recurrence after resection for hepatocellular carcinoma and outcomes. J Am Coll Surg 2006;202:275-83.

14. Shah SA, Cleary SP, Wei AC, et al. Recurrence after liver resection for hepatocellular carcinoma: risk factors, treatment, and outcomes. Surgery 2007;141:330-9.

15. Nakano R, Ohira M, Kobayashi T, et al. Hepatectomy versus stereotactic body radiotherapy for primary early hepatocellular carcinoma: A propensity-matched analysis in a single institution. Surgery 2018;164:219-26.

16. Su F, Chen KH, Liang ZG, et al. Comparison of threedimensional conformal radiotherapy and hepatic resection in hepatocellular carcinoma with portal vein tumor thrombus. Cancer Med 2018;7:4387-95.

17. Yoon SM, Ryoo BY, Lee SJ, et al. Efficacy and Safety of Transarterial Chemoembolization Plus External Beam Radiotherapy vs Sorafenib in Hepatocellular Carcinoma With Macroscopic Vascular Invasion: A Randomized Clinical Trial. JAMA Oncol 2018;4:661-9.

18. Kalogeridi MA, Zygogianni A, Kyrgias G, et al. Role of radiotherapy in the management of hepatocellular carcinoma: A systematic review. World J Hepatol 2015;7:101-12.

19. Emami B, Lyman J, Brown A, et al. Tolerance of normal tissue to therapeutic irradiation. Int J Radiat Oncol Biol Phys 1991;21:109-22.

20. Folkert MR, Timmerman RD. Stereotactic ablative body radiosurgery (SABR) or Stereotactic body radiation therapy (SBRT). Adv Drug Deliv Rev 2017;109:3-14.

21. Dawson LA, Ten Haken RK. Partial volume tolerance of the liver to radiation. Semin Radiat Oncol 2005;15:279-83.

22. Ursino S, Greco C, Cartei F, et al. Radiotherapy and hepatocellular carcinoma: update and review of the literature. Eur Rev Med Pharmacol Sci 2012;16:1599-604.

23. Culleton S, Jiang H, Haddad CR, et al. Outcomes following definitive stereotactic body radiotherapy for patients with Child-Pugh B or C hepatocellular carcinoma. Radiother Oncol 2014;111:412-7.

24. Mornex F, Girard N, Beziat C, et al. Feasibility and efficacy of high-dose three-dimensional-conformal radiotherapy in cirrhotic patients with small-size hepatocellular carcinoma non-eligible for curative therapies--mature results of the 
French Phase II RTF-1 trial. Int J Radiat Oncol Biol Phys 2006;66:1152-8.

25. Park W, Lim DH, Paik SW, et al. Local radiotherapy for patients with unresectable hepatocellular carcinoma. Int J Radiat Oncol Biol Phys 2005;61:1143-50.

26. Korean Liver Cancer Study G, National Cancer Center K. Practice guidelines for management of hepatocellular carcinoma 2009. Korean J Hepatol 2009;15:391-423.

27. Benson AB, 3rd, D'Angelica MI, Abbott DE, et al. NCCN Guidelines Insights: Hepatobiliary Cancers, Version 1.2017. J Natl Compr Canc Netw 2017;15:563-73.

28. Nakayama H, Sugahara S, Tokita M, et al. Proton beam therapy for hepatocellular carcinoma: the University of Tsukuba experience. Cancer 2009;115:5499-506.

29. Fukumitsu N, Sugahara S, Nakayama H, et al. A prospective study of hypofractionated proton beam therapy for patients with hepatocellular carcinoma. Int J Radiat Oncol Biol Phys 2009;74:831-6.

30. Komatsu S, Fukumoto T, Demizu Y, et al. Clinical results and risk factors of proton and carbon ion therapy for hepatocellular carcinoma. Cancer 2011;117:4890-904.

31. Ricke J, Wust P, Stohlmann A, et al. CT-Guided brachytherapy. A novel percutaneous technique for interstitial ablation of liver metastases. Strahlenther Onkol 2004;180:274-80.

32. Liu YE, Zong J, Ren XC, et al. High-intensity focused ultrasound combined with transcatheter arterial chemoembolization and radiotherapy for advanced hepatocellular carcinoma: A case report. Medicine (Baltimore) 2019;98:e16660.

33. Cheng SH, Lin YM, Chuang VP, et al. A pilot study of three-dimensional conformal radiotherapy in unresectable hepatocellular carcinoma. J Gastroenterol Hepatol 1999;14:1025-33.

34. Rim CH, Kim CY, Yang DS, et al. Comparison of radiation therapy modalities for hepatocellular carcinoma with portal vein thrombosis: A meta-analysis and systematic review. Radiother Oncol 2018;129:112-22.

35. Zhao JD, Xu ZY, Zhu J, et al. Application of active breathing control in 3-dimensional conformal radiation therapy for hepatocellular carcinoma: the feasibility and benefit. Radiother Oncol 2008;87:439-44.

36. Dawson LA, Brock KK, Kazanjian S, et al. The reproducibility of organ position using active breathing control (ABC) during liver radiotherapy. Int J Radiat Oncol Biol Phys 2001;51:1410-21.

37. Giraud P, Yorke E, Jiang S, et al. Reduction of organ motion effects in IMRT and conformal $3 \mathrm{D}$ radiation delivery by using gating and tracking techniques. Cancer Radiother 2006;10:269-82.

38. Park HC, Seong J, Han KH, et al. Dose-response relationship in local radiotherapy for hepatocellular carcinoma. Int J Radiat Oncol Biol Phys 2002;54:150-5.

39. Lim DH, Lee H, Park HC, et al. The efficacy of high-dose 3-dimensional conformal radiation therapy in patients with small hepatocellular carcinoma not eligible for other local modalities. Am J Clin Oncol 2013;36:162-6.

40. Su F, Chen K, Liang Z, et al. Survival benefit of higher fraction dose delivered by three-dimensional conformal radiotherapy in hepatocellular carcinoma smaller than 10 cm in size. Cancer Manag Res 2019;11:3791-9.

41. Kong M, Hong SE. Optimal follow-up duration for evaluating objective response to radiotherapy in patients with hepatocellular carcinoma: a retrospective study. Chin J Cancer 2015;34:79-85.

42. Lichter AS, Ten Haken RK. Three-dimensional treatment planning and conformal radiation dose delivery. Important Adv Oncol 1995:95-109.

43. Tang QH, Li AJ, Yang GM, et al. Surgical resection versus conformal radiotherapy combined with TACE for resectable hepatocellular carcinoma with portal vein tumor thrombus: a comparative study. World J Surg 2013;37:1362-70.

44. Rim CH, Yang DS, Park YJ, et al. Effectiveness of highdose three-dimensional conformal radiotherapy in hepatocellular carcinoma with portal vein thrombosis. Jpn J Clin Oncol 2012;42:721-9.

45. Kouloulias V, Mosa E, Georgakopoulos J, et al. Threedimensional conformal radiotherapy for hepatocellular carcinoma in patients unfit for resection, ablation, or chemotherapy: a retrospective study. Scientific World Journal 2013;2013:780141.

46. Yoon SM, Lim YS, Won HJ, et al. Radiotherapy plus transarterial chemoembolization for hepatocellular carcinoma invading the portal vein: long-term patient outcomes. Int J Radiat Oncol Biol Phys 2012;82:2004-11.

47. Ulger S, Cetin E, Catli S, et al. Intensity-Modulated Radiation Therapy Improves the Target Coverage Over 3-D Planning While Meeting Lung Tolerance Doses for All Patients With Malignant Pleural Mesothelioma. Technol Cancer Res Treat 2017;16:332-8.

48. Ding X, Dionisi F, Tang S, et al. A comprehensive dosimetric study of pancreatic cancer treatment using three-dimensional conformal radiation therapy (3DCRT), intensity-modulated radiation therapy (IMRT), volumetric-modulated radiation therapy (VMAT), and 
passive-scattering and modulated-scanning proton therapy (PT). Med Dosim 2014;39:139-45.

49. Kang MK, Kim MS, Kim SK, et al. High-dose radiotherapy with intensity-modulated radiation therapy for advanced hepatocellular carcinoma. Tumori 2011;97:724-31.

50. Wang WH, Wang Z, Wu JX, et al. Survival benefit with IMRT following narrow-margin hepatectomy in patients with hepatocellular carcinoma close to major vessels. Liver Int 2015;35:2603-10.

51. Wang L, Wang W, Yao X, et al. Postoperative adjuvant radiotherapy is associated with improved survival in hepatocellular carcinoma with microvascular invasion. Oncotarget 2017;8:79971-81.

52. Yu W, Wang W, Rong W, et al. Adjuvant radiotherapy in centrally located hepatocellular carcinomas after hepatectomy with narrow margin $(<1 \mathrm{~cm})$ : a prospective randomized study. J Am Coll Surg 2014;218:381-92.

53. Zhang T, Zhao YT, Wang Z, et al. Efficacy and Safety of Intensity-Modulated Radiotherapy Following Transarterial Chemoembolization in Patients With Unresectable Hepatocellular Carcinoma. Medicine (Baltimore) 2016;95:e3789.

54. Wang PM, Hsu WC, Chung NN, et al. Radiotherapy with volumetric modulated arc therapy for hepatocellular carcinoma patients ineligible for surgery or ablative treatments. Strahlenther Onkol 2013;189:301-7.

55. Chen D, Wang R, Meng X, et al. A comparison of liver protection among 3-D conformal radiotherapy, intensitymodulated radiotherapy and RapidArc for hepatocellular carcinoma. Radiat Oncol 2014;9:48.

56. Schaub SK, Hartvigson PE, Lock MI, et al. Stereotactic Body Radiation Therapy for Hepatocellular Carcinoma: Current Trends and Controversies. Technol Cancer Res Treat 2018;17:1533033818790217.

57. Lazarev S, Hardy-Abeloos C, Factor O, et al. Stereotactic body radiation therapy for centrally located hepatocellular carcinoma: outcomes and toxicities. J Cancer Res Clin Oncol 2018;144:2077-83.

58. Bujold A, Massey CA, Kim JJ, et al. Sequential phase I and II trials of stereotactic body radiotherapy for locally advanced hepatocellular carcinoma. J Clin Oncol 2013;31:1631-9.

59. Andolino DL, Johnson CS, Maluccio M, et al. Stereotactic body radiotherapy for primary hepatocellular carcinoma. Int J Radiat Oncol Biol Phys 2011;81:e447-53.

60. Kwon JH, Bae SH, Kim JY, et al. Long-term effect of stereotactic body radiation therapy for primary hepatocellular carcinoma ineligible for local ablation therapy or surgical resection. Stereotactic radiotherapy for liver cancer. BMC Cancer 2010;10:475.

61. Sanuki N, Takeda A, Oku Y, et al. Stereotactic body radiotherapy for small hepatocellular carcinoma: a retrospective outcome analysis in 185 patients. Acta Oncol 2014;53:399-404.

62. Takeda A, Oku Y, Sanuki N, et al. Dose volume histogram analysis of focal liver reaction in follow-up multiphasic CT following stereotactic body radiotherapy for small hepatocellular carcinoma. Radiother Oncol 2012;104:374-8.

63. Rajyaguru DJ, Borgert AJ, Smith AL, et al. Radiofrequency Ablation Versus Stereotactic Body Radiotherapy for Localized Hepatocellular Carcinoma in Nonsurgically Managed Patients: Analysis of the National Cancer Database. J Clin Oncol 2018;36:600-8.

64. Wahl DR, Stenmark MH, Tao Y, et al. Outcomes After Stereotactic Body Radiotherapy or Radiofrequency Ablation for Hepatocellular Carcinoma. J Clin Oncol 2016;34:452-9.

65. Chan LC, Chiu SK, Chan SL. Stereotactic radiotherapy for hepatocellular carcinoma: report of a local singlecentre experience. Hong Kong Med J 2011;17:112-8.

66. Ibarra RA, Rojas D, Snyder L, et al. Multicenter results of stereotactic body radiotherapy (SBRT) for non-resectable primary liver tumors. Acta Oncol 2012;51:575-83.

67. Rackwitz T, Debus J. Clinical applications of proton and carbon ion therapy. Semin Oncol 2019;46:226-32.

68. Brahme A, Kallman P, Lind BK. Optimization of proton and heavy ion therapy using an adaptive inversion algorithm. Radiother Oncol 1989;15:189-97.

69. Nakayama H, Sugahara S, Fukuda K, et al. Proton beam therapy for hepatocellular carcinoma located adjacent to the alimentary tract. Int J Radiat Oncol Biol Phys 2011;80:992-5.

70. Lee SU, Park JW, Kim TH, et al. Effectiveness and safety of proton beam therapy for advanced hepatocellular carcinoma with portal vein tumor thrombosis. Strahlenther Onkol 2014;190:806-14.

71. Imada H, Kato H, Yasuda S, et al. Comparison of efficacy and toxicity of short-course carbon ion radiotherapy for hepatocellular carcinoma depending on their proximity to the porta hepatis. Radiother Oncol 2010;96:231-5.

72. Antoch G, Mueller SP, Hamami M, et al. Selective internal radiotherapy (SIRT) for hepatocellular carcinoma. Rofo 2010;182:660-70.

73. Geschwind JF, Salem R, Carr BI, et al. Yttrium-90 
microspheres for the treatment of hepatocellular carcinoma. Gastroenterology 2004;127:S194-205.

74. Mantry PS, Mehta A, Madani B, et al. Selective internal radiation therapy using yttrium-90 resin microspheres in patients with unresectable hepatocellular carcinoma: a retrospective study. J Gastrointest Oncol 2017;8:799-807.

75. Wang N, Mao L, Yang L, et al. Resveratrol protects against early polymicrobial sepsis-induced acute kidney injury through inhibiting endoplasmic reticulum stress-activated NF-kappaB pathway. Oncotarget

Cite this article as: Chen W, Chiang CL, Dawson LA. Efficacy and safety of radiotherapy for primary liver cancer. Chin Clin Oncol 2021;10(1):9. doi: 10.21037/cco-20-89
2017;8:36449-61.

76. Carr BI, Kondragunta V, Buch SC, et al. Therapeutic equivalence in survival for hepatic arterial chemoembolization and yttrium 90 microsphere treatments in unresectable hepatocellular carcinoma: a two-cohort study. Cancer 2010;116:1305-14.

77. Oladeru OT, Miccio JA, Yang J, et al. Conformal external beam radiation or selective internal radiation therapy-a comparison of treatment outcomes for hepatocellular carcinoma. J Gastrointest Oncol 2016;7:433-40. 